\title{
PHB - Bio Based and Biodegradable Replacement for PP: A Review
}

\author{
Erich Markl*, Hannes Grünbichler and Maximilian Lackner \\ Department of Advanced Technologies, University of Applied Sciences, Austria
}

*Corresponding author: Erich Markl, Department of Advanced Technologies, University of Applied Sciences, Hoech staed platz 6, 1200, Vienna, Austria

Submission: July 23,2018; Published: September 05, 2018

\begin{abstract}
Food packaging today relies heavily on plastics such as PP (polypropylene) and PE (polyethylene), from which short-lived, cost-effective packaging materials are made. Their accumulation in the environment has becomes a significant concern. PHB (Polyhydroxy butyrate) is a naturally produced polyester, which can be used as biodegradable thermoplastics. PHB has similar properties to PP and is seen as sustainable replacement candidate for this fossil commodity polymer. PHB is biodegradable, also in the marine environment. Key benefits of PHB over PP are lower carbon footprint and avoidance of "white pollution", which manifests itself e.g. as marine debris and microplastics. Bioplastics today have a market share of only $2 \%$, and it is materials that can replace mass products such as PE and PP which can really pave the way for more sustainable plastics. PHB will play a key role here. In this review article, the state-of-the-art in $\mathrm{PHB}$ production and applications is discussed. $\mathrm{PHB}$ can be produced from sugar, but also from $\mathrm{CO}_{2}$ using cyanobacteria. Applications include packaging in general and food packaging in, a major field for short-lived plastics products where biodegradability is a strong benefit.
\end{abstract}

\section{Introduction}

Bioplastics are polymer-based products which are either biobased and/or biodegradable [1], according to certain standards such as biobased carbon content by the carbon 14 content [2] or biodegradability according to EN 13432 [3]. Today, bioplastics have a market share of approx. 2\%, according to Endres [4]. Common bioplastics are starch, thermoplastic starch (TPS), polylactic acid (PLA), polybutylene adipate terephthalate (PBAT) [5] and polyhydroxy butyrate (PHB). Common products are cutlery, organic waste bags, shopping bags, flexible and rigid packaging, and consumer goods. There also exist partly bio based "conventional" plastics such as sugar-cane-derived polyethylene (PE) [6], which are considered bioplastics despite their non-biodegradability Figure 1 shows the similarity of PHB and PP graphically.

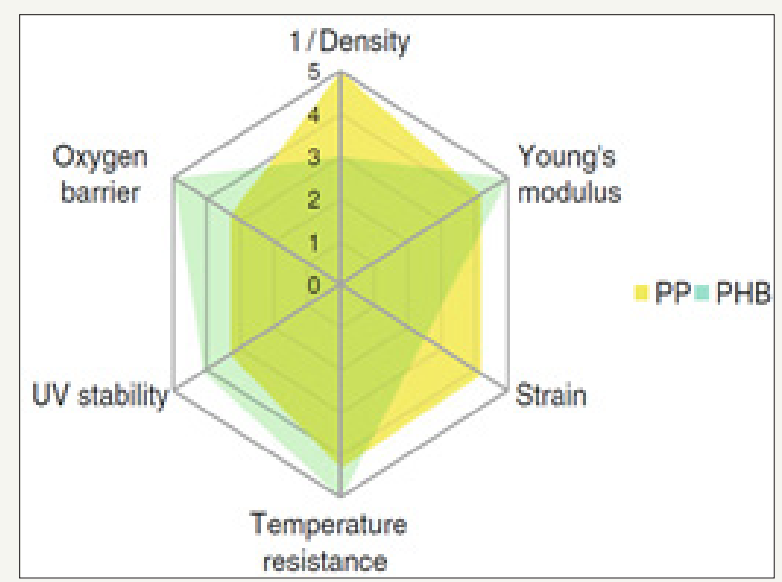

Figure 1: Diagram comparing PHB and PP reproduced [7].

\section{PHB - A Sustainable Bioplastics Material}

Polyhydroxy butyrate (PHB) is a polyhydroxyalkanoate (PHA), a class of naturally occurring polyesters. PHB is the most common
PHA. It is biodegradable, also in the marine environment. The annual production capacity of PHB is estimated at approx. 30,000 tons [7], which is rather small looking at the global PP production 
of around 65 million tons per year [8]. Table 1 compares the properties of PHB to those of PP. One can see a striking similarity. PHB was first introduced into the market in 1982 [9]. The classic production process uses microorganisms that ferment organic matter. For instance, the bacterium Alcaligenes eutrophus can produce up to $80 \%$ of its dry cell weight PHB when a mixture of glucose and propionic acid is fed as nutrient [10]. The process, however, is expensive and subject to the same discussion as first generation biofuels over sustainability [11]. There is also a catalytic process, the alternating copolymerization of carbon monoxide and propylene oxide or the ring-opening polymerization of b-butyrolactone, as described by Reichardt and Rieger [10]. A novel approach is to use cyanobacteria to convert $\mathrm{CO}_{2}$ into $\mathrm{PHB}$, which some strains are known to do under nitrogen and phosphorous deficiency [12]. Recently, 37\% of dry cell weight PHB were reported in cyanobacteria by Kamravamanesh et al. [12].

Table 1: Properties of PHB compared to those of PP Source [9].

\begin{tabular}{|c|c|c|}
\hline Property & PHB & PP \\
\hline Crystalline Melting point $\left({ }^{\circ} \mathrm{C}\right)$ & 175 & 176 \\
\hline Crystallinity $(\%)$ & 80 & 70 \\
\hline Molecular Weight (Daltons) & $5 \times 10^{5}$ & $2 \times 10^{5}$ \\
\hline Glass transition temperature $\left({ }^{\circ} \mathrm{C}\right)$ & 4 & -10 \\
\hline
\end{tabular}

\begin{tabular}{|c|c|c|}
\hline Density $\left(\mathrm{g} / \mathrm{cm}^{3}\right)$ & 1.250 & 0.905 \\
\hline Flexural modulus (Gpa) & 4 & 1.7 \\
\hline Tensile strength (Mpa) & 40 & 38 \\
\hline Extension to break (\%) & 6 & 400 \\
\hline Ultraviolet resistance & good & poor \\
\hline Solvent resistance & poor & good \\
\hline
\end{tabular}

\section{Applications of PHB in Food Packaging}

PHB was tested for food packaging successfully [13-15] and found to be more rigid and less flexible than PP [13]. In [16], Peelman et al. review the application of bioplastics for food packaging in general. Levkane et al. [17] studied the effect of pasteurization on a meat salad packed in conventional (PE, PP) and bio-based packaging (PLA, PHB). The authors found that PHB films could be successfully used to pack that kind of food. Bucci et al. [14] found out that PP can be replaced by PHB for the packaging of fatty products (mayonnaise, margarine and cream cheese) [17]. The authors checked physical, mechanical, sensorial and dimensional parameters. Nanoparticles in PHB were found to improve the properties for food packaging [18]. Haugaard et al. [19] found out that orange juice and dressing packed in PHB showed the same stability as in HDPE, implying that the material is suitable for liquid acidic and fatty foodstuff.

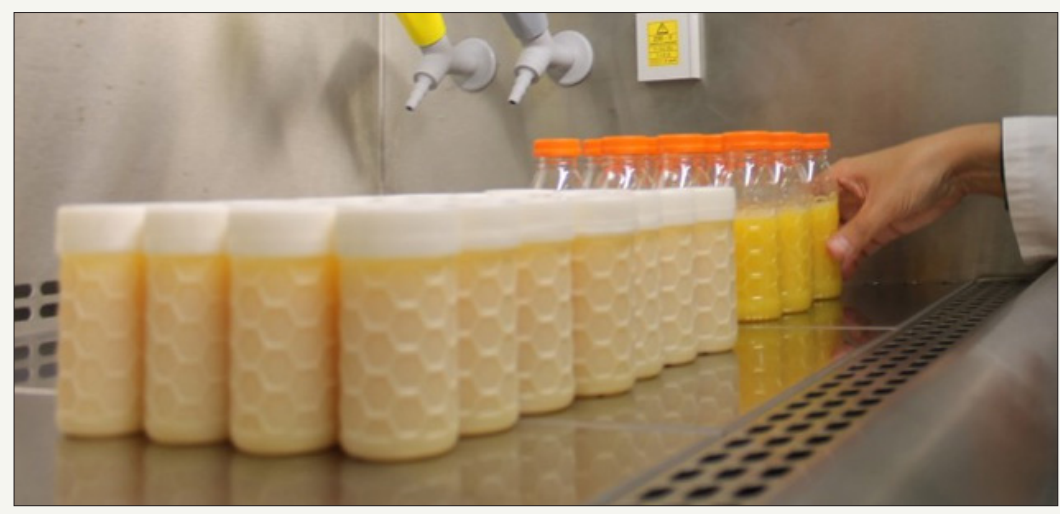

Figure 2: Bottles made from PHA [23].

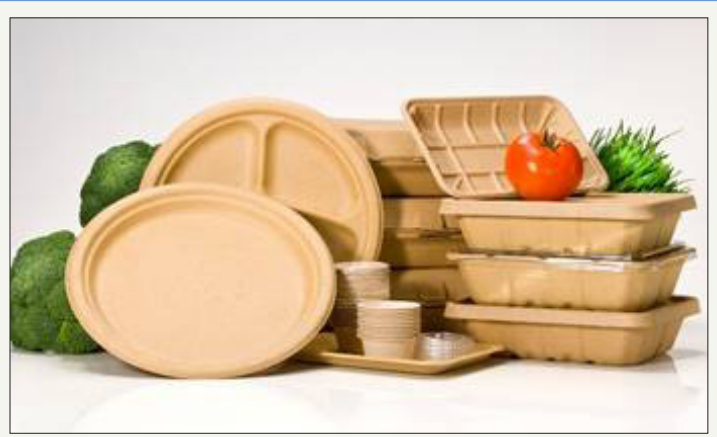

Figure 3: Extrusion-coated material using PHA [24].

Muizniece et al. [20] stated that PHB materials are suitable materials for storage of sour cream. Polyhydroxyalkanoate-based multilayer structures for food packaging are described by Fabra et al. [21] where a zein interlayer could strongly increase the oxygen barrier. It is known that copolymers have improved properties over PHB, e.g. PHBV. PHBV stands for (poly-(3-hydroxybutyrate-co-3hydroxyvalerate). The comonomer can reduce the glass transition and melting temperature, making the material less brittle and 
broadening the processing window [21]. In general, bioplastics are more temperature-sensitive than conventional, fossil polymers [22-24]. Figure $2 \& 3$ show typical food packaging examples made from PHA [25].

Bioplastics can be a marketing argument such as "organic food". One must study whether they bring a tangible sustainability advantage. The environmental impact of biodegradable food packaging when considering food waste is discussed by Dikes et al. [26], since it was found that approx. $50 \%$ of the environmental impact of food packaging stems from the thrown-away food contained therein, regardless of whether the packaging is biodegradable or not. Figure 4 shows the comparison of a PP package with one made from PHA and TPS. Dilkes et al. [26] found out that shows that also and particularly for biodegradable packaging, reducing food waste is a key design criterion for success. In fact, the negative environmental impacts associated with disposal of a PHA-TPS packaging in landfills with low gas capture rates $\left(\mathrm{CH}_{4}\right.$ emissions from anaerobic digestion, high GWP) can be offset if the package reduces food wastage (meat) by approximately 6\% [26]. So, industry not only needs bioplastics such as PHB instead of PP, but also novel concepts for food packaging to avoid discarding foodstuff unnecessarily by the consumers.

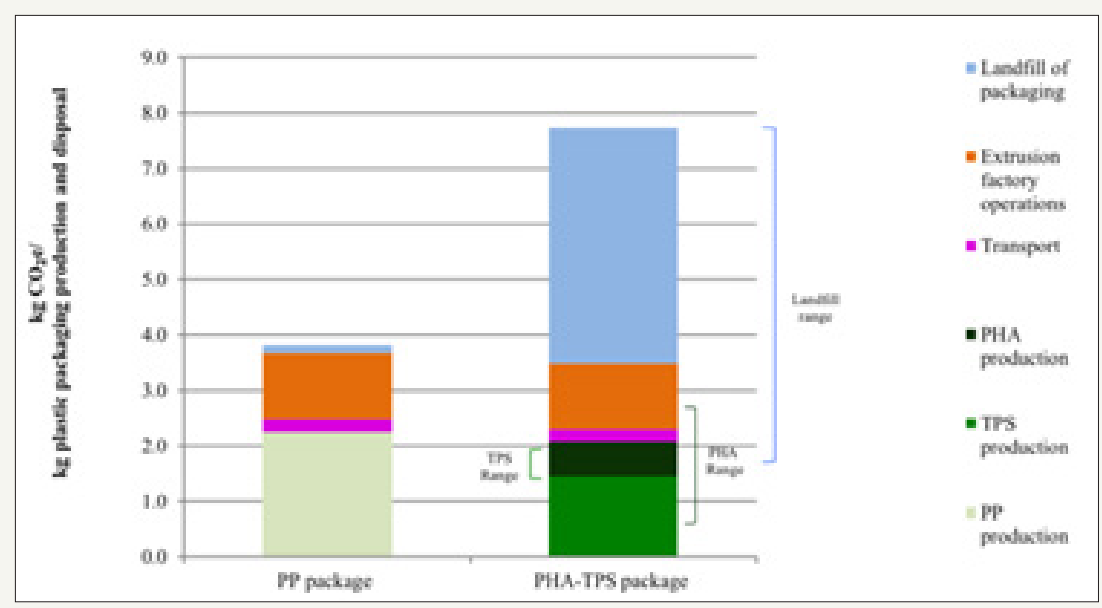

Figure 4: $\mathrm{Kg} \mathrm{CO}_{2 \mathrm{e}}$ emissions (GWP100) for the production and disposal of $1 \mathrm{~kg}$ of PP or PHA-TPS food packaging. GWP100=greenhouse warming potential with a 100 -year horizon.

\section{Conclusion}

In this mini-review, the biopolymer PHB (polyhydroxy butyrate) was discussed as potential bio-based and biodegradable replacement candidate for the fossil commodity plastics PP (polypropylene). Although the global production capacity of PHB at around 30,000 tons/year is less than $0.1 \%$ that of PP, it enjoys high annual growth rates. Recently, significant advancements to produce $\mathrm{PHB}$ from $\mathrm{CO}_{2}$ and sunlight were made, as described by Kamravamanesh et al. [12,13], so eventually, in the blue economy [27], PHB bioplastics will be able to replace PP for food packaging. Bioplastics are necessary, because an estimated $30 \%$ of plastic packaging materials may never be eligible for recycling or reuse [28]. "I Have a Dream and it's Green", D. Chandra Mohan stated in a recent paper. Let's share this dream and put it into practice.

\section{References}

1. Maximilian L (2015) Bioplastics. In: Kirk other encyclopedia of chemical technology, p. 18.

2. ASTM D6866 - 18, Standard Test Methods for Determining the Biobased Content of Solid, Liquid, and Gaseous Samples Using Radiocarbon Analysis.

3. (2000) DIN EN 13432:2000-12, Packaging-Requirements for packaging recoverable through composting and biodegradation-Test scheme and evaluation criteria for the final acceptance of packaging; German version EN 13432.
4. Hans JE, Andrea SR (2011) Engineering Biopolymers: Markets, Manufacturing, Properties and Applications, Carl Hanser Verlag GmbH \& Co KG, Germany.

5. Maximilian L (2016) PBAT-A versatile material for biodegradable and compostable packagings, 4th International Conference on Sustainable Bioplastics, Alicante, Spain.

6. Brazilian plant to make polyethylene from sugar cane, Pump Industry Analyst 2017(8): 3-4.

7. Maximilian L, Biofuels (2017) In: Handbook of Climate Change Mitigation and Adaptation Chen, Wei-Yin, Suzuki, Toshio, Lackner, Maximilian (Eds.), Springer, New York, USA, ISBN: 978-3-319-14410-14418.

8. https://www.plasticseurope.org/application/files/5715/1717/4180/ Plastics_the_facts_2017_FINAL_for_website_one_page.pdf

9. David L (1998) Kaplan, Biopolymers from Renewable Resources, Springer, ISBN: 978-3540635673

10. Robert R, Bernhard R (2012) Poly(3-Hydroxybutyrate) from Carbon Monoxide. In: Synthetic Biodegradable Polymers, Rieger B, Künkel A, Coates GW, Reichardt R, Dinjus E, Zevaco A (Eds.), Springer, ISBN 9783-642-27154-0.

11. Maximilian L, Biofuels (2017) In: Handbook of Climate Change Mitigation and Adaptation Chen, Wei-Yin, Suzuki, Toshio, Lackner, Maximilian (Eds.), Springer, New York, USA, ISBN: 978-3-319-14410-14418.

12. Kamravamanesh D, Pflügl S, Nischkauer W, Limbeck A, Lackner M, et al. (2017) Photosynthetic poly- $\beta$-hydroxybutyrate accumulation in unicellular cyanobacterium Synechocystis sp. PCC 6714 . AMB Express 7(1): 143 . 
13. Kamravamanesh D, Stefan P, Tamas K, Irina D, Paul K (2018) Maximilian, Lackner, Christoph Herwig, Increased poly-beta-hydroxybutyrate production from $\mathrm{CO}_{2}$ in randomly mutated cells of cyanobacterial strain Synechocystis sp. PCC 6714: mutant generation and characterization, Bioresource Technology.

14. Bucci DZ, Tavares LBB, Sell I (2007) Biodegradation and physical evaluation of PHB packaging. Polymer Testing 26(7): 908-915.

15. Masood F (2017) Polyhydroxyalkanoates in the food packaging industry. Nanotechnology Applications in Food, pp. 153-177.

16. Nanou P, Peter R, Bruno De M, Dimitri A, Frank D (2013) Application of bioplastics for food packaging. Trends in Food Science \& Technology 32(2): 128-141.

17. Levkane V, Muizniece BS, Dukalska L (2008) Pasteurization effect to quality of salad with meat and mayonnaise. Foodbalt. pp. 69-73.

18. Khosravi D, Bucci DZ (2015) Application of poly(hydroxyalkanoate) In food packaging: improvements by nanotechnology. Chem Biochem Eng Q 29(2): 275-285.

19. Haugaard K, Danielsen B, Bertelsen G (2003) Impact of polylactate and poly(hydroxybutyrate) on food quality. European Food Research \& Technology 216(3): 233-240.

20. Muizniece B, Dukalska L (2006) Impact of biodegradable PHB packaging composite materials on dairy product quality. Proceedings of the Latvia University of Agriculture 16 (311): 79-87.
21. María JF, Gloria S, Amparo LR, José ML (2014) Microbiological and ageing performance of polyhydroxyalkanoate-based multilayer structures of interest in food packaging, LWT. Food Science and Technology 59(2): 760-767.

22. Sunny M, Kurt K, Yael V (2011) Assessment of PHB with varying hydroxy valerate content for potential packaging applications. European Polymer Journal 47(2): 179-186.

23. Marina PA, Juan L, Alberto H, Emilio R (2014) Ternary PLA-PHBLimonene blends intended for biodegradable food packaging applications. European Polymer Journal 50: 55-270.

24. Sustainable B (2016) Bioplastic advancements show promise for biodegradable milk, juice, food Packaging.

25. Unique naturally biodegradable food packaging material launched that is fully recyclable.

26. Leela S, Dilkes H, Joe LL, Tim G, Steven P, et al. (2018) Environmental impact of biodegradable food packaging when considering food waste. Journal f Cleaner Production 180: 325-334.

27. Ellen MF (2017) The New Plastics Economy e Catalyzing Action, AS Ninawe. blue economy is the economic activities that directly or indirectly take place in the ocean and seas, Use Outputs, Goods and services into ocean and land based activities. Examines Mar Biol Oceanogr 1(1): EMBO.000501.

28. Chandra MD (2018) I have a dream and it's green. Res Dev Material Sci 4(2): RDMS.000583.

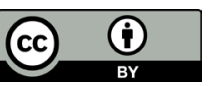

Creative Commons Attribution 4.0

International License

For possible submissions Click Here
Submit Article

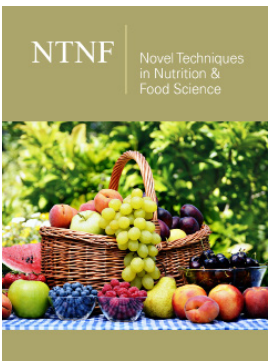

Novel Techniques in Nutrition and Food Science

\section{Benefits of Publishing with us}

- High-level peer review and editorial services

- Freely accessible online immediately upon publication

- Authors retain the copyright to their work

- Licensing it under a Creative Commons license

- Visibility through different online platforms 